\title{
Organization of Dietary Control for Nutrition-Training Intervention Involving Periodized Carbohydrate Availability and Ketogenic Low-Carbohydrate High-Fat Diet
}

\author{
Joanne G. Mirtschin, Sara F. Forbes, and Louise E. Cato \\ Australian Institute of Sport \\ Ida A. Heikura \\ Australian Institute of Sport and Australian Catholic University \\ Nicki Strobel \\ University College Zealand \\ Rebecca Hall \\ Australian Institute of Sport \\ Louise M. Burke \\ Australian Institute of Sport and Australian Catholic University
}

\begin{abstract}
The authors describe the implementation of a 3-week dietary intervention in elite race walkers at the Australian Institute of Sport, with a focus on the resources and strategies needed to accomplish a complex study of this scale. Interventions involved: traditional guidelines of high carbohydrate $(\mathrm{CHO})$ availability for all training sessions; a periodized $\mathrm{CHO}$ diet which integrated sessions with low and high $\mathrm{CHO}$ availability within the same total $\mathrm{CHO}$ intake; and a ketogenic low-CHO high-fat diet. Sevenday menus and recipes were constructed for a communal eating setting to meet nutritional goals as well as individualized food preferences and special needs. Menus also included nutrition support before, during, and after exercise. Daily monitoring, via observation and food checklists, showed that energy and macronutrient targets were achieved. Diets were matched for energy $(\sim 14.8 \mathrm{MJ} / \mathrm{d})$ and protein $\left(\sim 2.1 \mathrm{~g} \cdot \mathrm{kg}^{-1} \cdot \mathrm{day}^{-1}\right)$ and achieved desired differences for fat and CHO, with high CHO availability and periodized $\mathrm{CHO}$ availability: $\mathrm{CHO}=8.5 \mathrm{~g} \cdot \mathrm{kg}^{-1} \cdot \mathrm{day}^{-1}, 60 \%$ energy, fat $=20 \%$ of energy and low-CHO high-fat diet: $0.5 \mathrm{~g} \cdot \mathrm{kg}^{-1} \cdot \mathrm{day}^{-1} \mathrm{CHO}$, fat $=78 \%$ energy. There were no differences in micronutrient intake or density between the high $\mathrm{CHO}$ availability and periodized $\mathrm{CHO}$ availability diets; however, the micronutrient density of the low-CHO high-fat diet was significantly lower. Daily food costs per athlete were similar for each diet ( AU\$ $27 \pm 10)$. Successful implementation and monitoring of dietary interventions in sports nutrition research of the scale of the present study require meticulous planning and the expertise of chefs and sports dietitians. Different approaches to sports nutrition support raise practical challenges around cost, micronutrient density, accommodation of special needs, and sustainability.
\end{abstract}

Keywords: dietary standardization, LCHF diet, research methodology

The increasing interest in the implementation of special dietary interventions in both the practice and research settings of sports nutrition creates a number of challenges. First, the athlete/researcher must have a thorough understanding of the principles behind the intervention. This must be integrated with expert knowledge of food composition and menu planning to translate nutrient targets or dietary philosophies into food choices

\footnotetext{
Mirtschin, Forbes, Cato, Heikura, Hall, and Burke are with Sports Nutrition, Australian Institute of Sport, Canberra, Australian Capital Territory, Australia. Heikura and Burke are also with the Mary MacKillop Institute for Health Research, Australian Catholic University, Melbourne, Victoria, Australia. Strobel is with University College Zealand, Sorø, Denmark. Address author correspondence to Louise M. Burke at louise.burke@ausport.gov.au.
}

and meal patterns. Expertise is then needed to implement theoretical menus in real life. Practical issues include expense; food availability; opportunities and resources for preparing, storing, and consuming food; personal preferences and cultural practices around eating; and dietary intolerances or allergies. It can be difficult to individualize an eating plan that takes all these elements into account, but in the case of feeding groups of athletes, such as in a communal dining hall or a multisubject research project, menu development becomes even more challenging. Finally, research projects typically require monitoring of individual intake, particularly where compliance with the intervention needs to be maximized and documented. Failure to recognize these elements and/or the lack of expertise to master them frequently impairs the implementation of desired sports 
nutrition practices or the conduct of robust sports nutrition research.

The authors recently investigated three different dietary approaches to nutritional support for intensified training in a cohort of elite race walkers (Burke et al., 2017). This project was conducted in a residential camp setting with prescription and monitoring of training and diet. The current paper describes the process of implementing these dietary interventions, with multiple aims: (a) to define and illustrate nutrition practices and food choices of three different sports nutrition philosophies (high carbohydrate [CHO] availability [HCHO], periodized $\mathrm{CHO}$ availability [PCHO], and the ketogenic low-CHO, highfat [LCHF] diet), noting that these seem to be misunderstood across the scientific literature, social media, and lay practice (Burke, 2015); (b) to describe the process of implementing strict dietary control and monitoring of participant compliance with a nutrition-training intervention; and (c) to consider some of the practical implications of these three sports nutrition philosophies. The outcomes should both enhance the implementation of these sports nutrition philosophies in real-life practice and improve appreciation of the rigor with which sports nutrition research should be conducted.

\section{Methods}

The study involved a 3-week structured program of intensified training at the Australian Institute of Sport, with participants living in athlete residences and undertaking all meals and training sessions under supervision. The participants were race walkers with international race experience, ranging from world-class athletes to highly trained competitors. The study took place at two separate training camps, in November $2015(n=10)$ and January 2016 $(n=19)$, representing baseline preparation for the 2016 International Association of Athletics Federations race-walking season and the 2016 Olympic Games qualification period. Full details on subject characteristics, study methods, and test outcomes are provided elsewhere (Burke et al., 2017).

\section{Summary of Dietary Interventions}

The intervention involved three different approaches to dietary support for the intensified training program. Table 1 provides greater detail of the implementation of the following dietary philosophies in relation to the training intervention:

a. HCHO: Overall macronutrient composition $\sim 8-9 \mathrm{~g} \cdot \mathrm{kg}$ body mass $(\mathrm{BM})^{-1} \cdot \mathrm{day}^{-1}$ and $\sim 60-65 \%$ of energy from $\mathrm{CHO}$, $\sim 1.5-2.0 \mathrm{~g} \cdot \mathrm{kg} \mathrm{BM}^{-1} \cdot \mathrm{day}^{-1}$ and $15-20 \%$ energy from protein and $20 \%$ fat; similar $\mathrm{CHO}$ intake from day to day, with $\mathrm{CHO}$ consumed before, during, and after training sessions. The diet represents sports nutrition guidelines from 1990s (Coyle, 1991), scaled to the body size and training loads of each athlete according to updated guidelines (Burke et al., 2004).

b. PCHO: Same overall macronutrient composition as HCHO, but spread differently between and within days according to fuel needs of training as well as to integrate some training sessions with $\mathrm{HCHO}$ (high muscle glycogen, $\mathrm{CHO}$ feeding during session) and others with low $\mathrm{CHO}$ availability (low preexercise glycogen, overnight fasting, or delayed postsession refueling). This strategy represents current guidelines (Thomas et al., 2016) and evolving evidence around benefits of strategic training with low CHO availability (Bartlett et al., 2015; Marquet et al., 2016).

c. LCHF: $75-80 \%$ fat, $15-20 \%$ protein, and $<50$ g/day CHO. This is a ketogenic diet following the guidelines previously reported (Volek \& Phinney, 2012) and utilized in a study undertaken with endurance cyclists (Phinney et al., 1983).

Since a primary goal of the study was to evaluate the dietary treatments without interference from large or different changes in body composition, each athlete's energy intake was set to provide energy availability of $\sim 40 \mathrm{kcal} \cdot \mathrm{kg}$ lean $\mathrm{BM}^{-1}$. day $^{-1}$. The real-world experience of a loss of fat mass of $\sim 1-1.5 \mathrm{~kg}$ over the 4-week period of diet intervention and testing was permitted, and each athlete could request additional food or drinks at meals or from designated snacks and "free snacks" according to hunger, increases in training load from baseline information, or fluctuations in BM above the glycogen/fluid shifts expected with the LCHF.

\section{Menu Development and Implementation}

Menu development and the meal/snack preparation were undertaken by a team including a professional chef, food service dietitians, and sports dietitians/nutritionists. A 7-day menu (Table 2) was constructed to provide variety while meeting the nutrient prescription of each dietary intervention. Each meal had a theme that could be diversified according to each dietary prescription and fine-tuned according to specific energy requirements or special needs or preferences of individual participants. For several meals within each rotation, $\mathrm{PCHO}$ tracked $\mathrm{HCHO}$ in providing meals with $\mathrm{HCHO}$. However, on other occasions, when low $\mathrm{CHO}$ availability was required before or after training sessions, $\mathrm{PCHO}$ required a separate menu (Table 3), which was repeated three times, with small improvements on each repetition based on participant feedback. The benefits of undertaking menu harmonization included (a) efficiency of food ordering and meal preparation for the research team and (b) an enhanced sense of communal eating for the participants.

Recipes were sourced from the chef's own expertise and commercial cookbooks (Papas \& Papas, 2015; Richoux, 2014), with yields calculated and recipes scaled for larger quantities. A list of approved products was established for ingredients, meal components, snacks, and drinks, with set protocols for the use of substitutes in the case of difficulties with product supply. A template for the menu based on a 65-kg athlete was created for each diet and then adjusted to form an individualized meal and snack plan for each athlete to meet energy goals and macronutrient targets to within $1 \mathrm{~g}(\mathrm{HCHO}$ and PCHO: $\mathrm{CHO}=8.5 \mathrm{~g} \cdot \mathrm{kg}^{-1} \cdot \mathrm{day}^{-1}$, protein $=2.1 \mathrm{~g} \cdot \mathrm{kg}^{-1} \cdot \mathrm{day}^{-1}$, fat $=$ $1.2 \mathrm{~g} \cdot \mathrm{kg}^{-1} \cdot \mathrm{day}^{-1}$; LCHF: $\mathrm{CHO}=0.5 \mathrm{~g} \cdot \mathrm{kg}^{-1} \cdot \mathrm{day}^{-1}$, protein $=$ $2.1 \mathrm{~g} \cdot \mathrm{kg}^{-1} \cdot \mathrm{day}^{-1}$, fat $=4.45 \mathrm{~g} \cdot \mathrm{kg}^{-1} \cdot \mathrm{day}^{-1}$ ). Foods with a prominent macronutrient content (e.g., juice for $\mathrm{CHO}$, lean meat for protein, and/ or cream/olive oil/butter for fat) were used to fine-tune energy and macronutrient intake at a meal. One participant's meal and snack plan was adapted in consideration of a peanut allergy and gluten/wheat intolerance, while personal food preferences (e.g., flavor of juice or type of cheese) were integrated where possible within some food choices. Each participant's daily meal and snack plan was crosschecked by another team member for accuracy. Finalized meal plans were brought to each meal to guide serving, record alterations to actual meal intake and keep track of snack intake.

Meals were freshly prepared each day according to the standardized recipes. Participants ate their meals in a designated group dining area, with individualized meals being weighed out for the athletes according to their meal plans using calibrated scales (accurate to $2 \mathrm{~g}$ ). Uneaten food was accounted for after the 


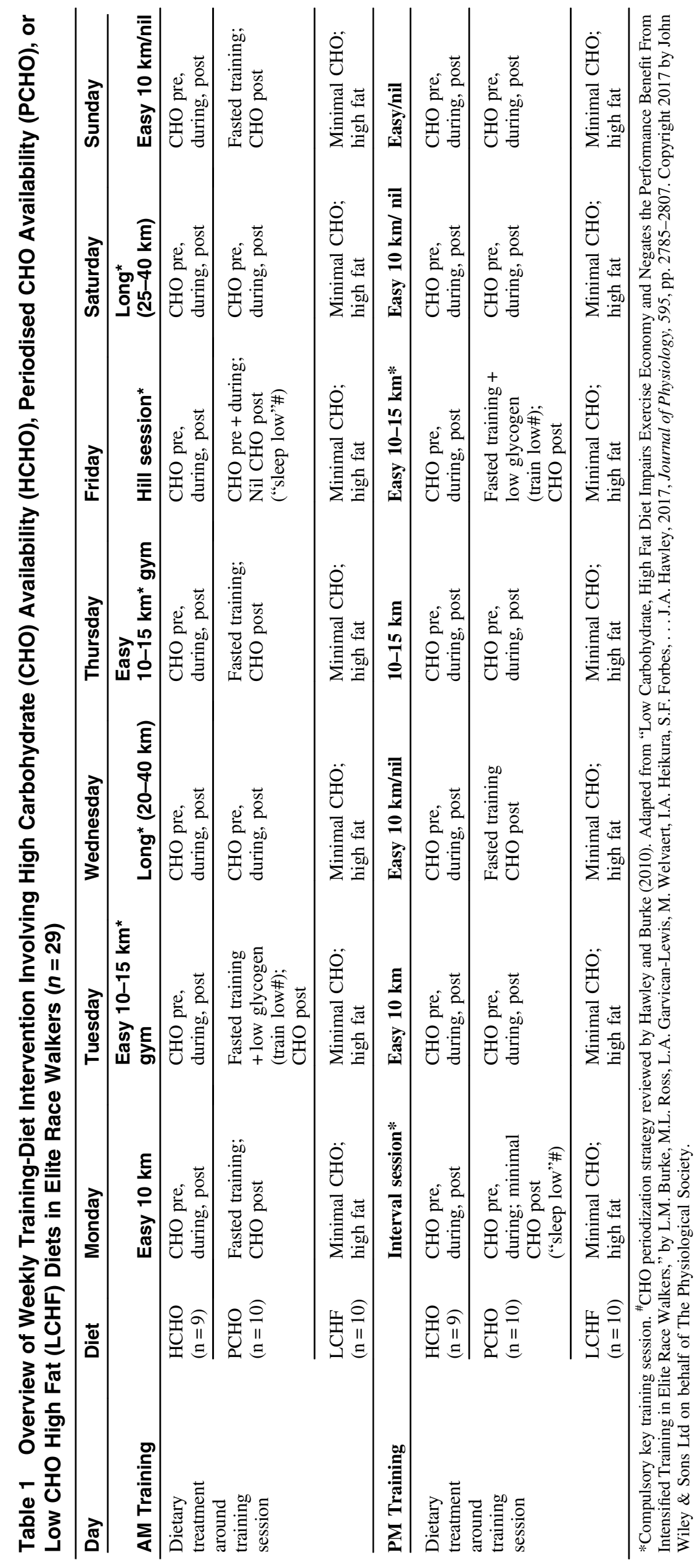




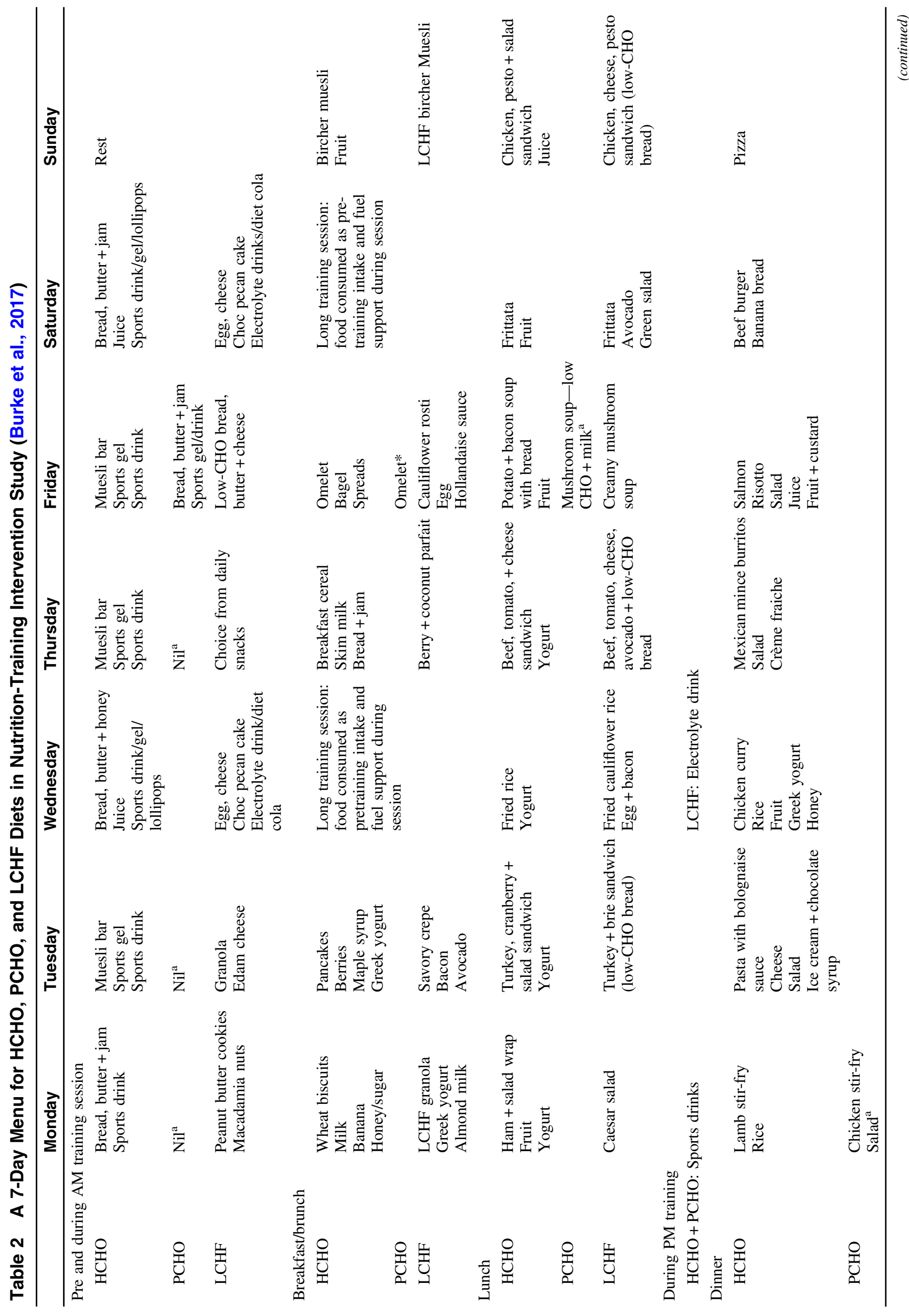




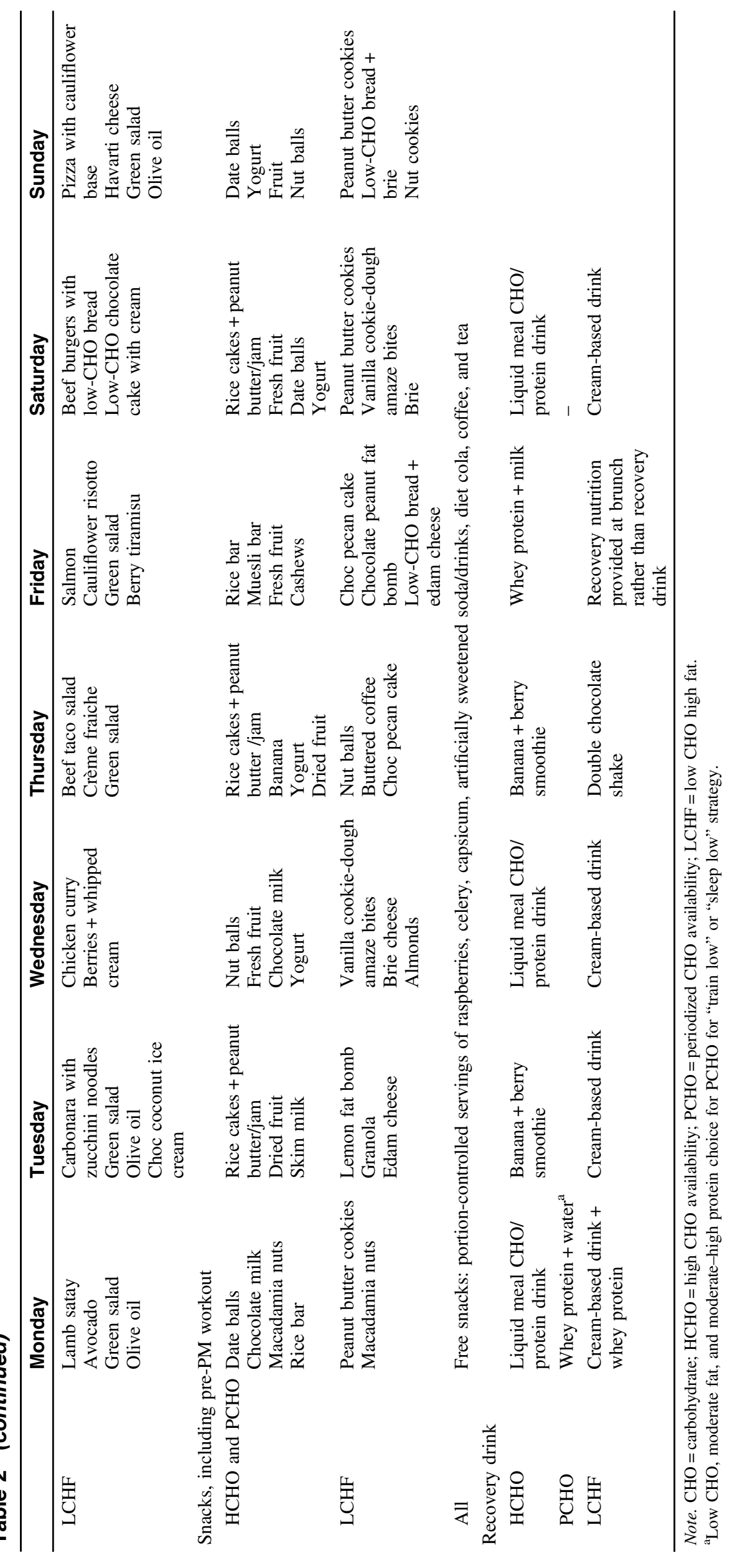

IJSNEM Vol. 28, No. 5, 2018 
Table 3 Examples of Meal in Which Three Separate but Integrated Menus Achieved Separate Nutritional Goals of $\mathrm{HCHO}, \mathrm{PCHO}$, and LCHF Diets in a Nutrition-Training Intervention (Burke et al., 2017)

\begin{tabular}{|c|c|c|c|}
\hline & $\mathrm{HCHO}$ & $\mathrm{PCHO}$ & LCHF \\
\hline Goals & $\begin{array}{l}\text { - Provide } \mathrm{CHO} \text { to promote muscle } \\
\text { glycogen resynthesis to fuel next } \\
\text { training session } \\
\text { - Provide moderate protein to } \\
\text { support posttraining adaptation } \\
\text { - Provide micronutrient-rich foods } \\
\text { to achieve micronutrient intake goals }\end{array}$ & $\begin{array}{l}\text { - Acutely restrict } \mathrm{CHO} \text { to limit glycogen } \\
\text { resynthesis after key workout, prolong- } \\
\text { ing the period of enhanced cellular } \\
\text { signaling while achieving low muscle } \\
\text { glycogen state for next training session } \\
\text { - Provide protein to support posttraining } \\
\text { adaptation, with increased intake } \\
\text { partially addressing CHO restriction } \\
\text { (energy deficit to be fully replaced at } \\
\text { next meal) } \\
\text { - Leave fat unchanged to allow } \\
\text { differentiation of effects of low CHO } \\
\text { availability from high fat intake } \\
\text { - Provide micronutrient-rich low-CHO } \\
\text { foods to achieve micronutrient goals and } \\
\text { increase meal volume }\end{array}$ & $\begin{array}{l}\text { - Chronically restrict } \mathrm{CHO} \text { to achieve } \\
\text { ongoing ketogenic state } \\
\text { - Provide moderate protein to } \\
\text { support posttraining adaptation but } \\
\text { avoid excessive opportunity for } \\
\text { gluconeogenesis } \\
\text { - Provide fat-rich foods and dressings to } \\
\text { reach target of } 75-80 \% \text { of energy from } \\
\text { fat, with focus on monosaturated and } \\
\text { saturated fatty acid sources } \\
\text { - Provide micronutrient-rich low-CHO } \\
\text { foods to achieve micronutrient goals and } \\
\text { increase volume of meal }\end{array}$ \\
\hline $\begin{array}{l}\text { Menu }(65-\mathrm{kg} \text { athlete } \\
\text { serve) }\end{array}$ & $\begin{array}{l}\text { Lamb stir-fry + rice (220 g stir-fry } \\
\text { and } 200 \mathrm{~g} \text { rice) }\end{array}$ & $\begin{array}{l}\text { Chicken stir-fry + salad ( } 450 \text { g stir-fry } \\
\text { and } 200 \mathrm{~g} \text { salad of lettuce, cucumber, } \\
\text { capsicum + tomato) }\end{array}$ & $\begin{array}{l}\text { Lamb satay + salad ( } 250 \mathrm{~g} \text { satay; } 150 \mathrm{~g} \\
\text { salad of lettuce, tomato + cucumber; } \\
60 \mathrm{~g} \text { avocado; and } 20 \mathrm{~g} \text { olive oil })\end{array}$ \\
\hline $\begin{array}{l}\text { Ingredients in main } \\
\text { dish }\end{array}$ & $\begin{array}{l}\text { Diced lamb, eggplant, capsicum, } \\
\text { zucchini, dried cranberries, lime } \\
\text { juice, chili, soy sauce, oyster sauce, } \\
\text { and sesame oil }\end{array}$ & $\begin{array}{l}\text { Diced chicken breast, zucchini, } \\
\text { capsicum, bok choy, broccoli, chili, } \\
\text { lime juice, soy sauce, and sesame oil }\end{array}$ & $\begin{array}{l}\text { Diced lamb, coconut cream, eggplant, } \\
\text { capsicum, cauliflower, peanut butter, } \\
\text { lime juice, chili, and soy sauce }\end{array}$ \\
\hline Energy $(\mathrm{kJ})$ & 2,379 & 1,490 & 2,495 \\
\hline Protein $(\mathrm{g})$ & 22 & 48 & 27 \\
\hline Fat $(\mathrm{g})$ & 11 & 12 & 61 \\
\hline CHO (g) & 90 & 10 & 8 \\
\hline
\end{tabular}

Note. $\mathrm{CHO}=$ carbohydrate; $\mathrm{HCHO}=$ high $\mathrm{CHO}$ availability; $\mathrm{PCHO}=$ periodized $\mathrm{CHO}$ availability; $\mathrm{LCHF}=$ low $\mathrm{CHO}$ high fat.

meal service. To allow for changes in hunger and satiety and to reduce the risk of large weight changes, participants were allowed to self-regulate at each meal, with any adjustments noted on their meal plan. For example, participants were permitted to leave unfinished meals/snacks or to request a larger meal as long as all components of the meal were provided and measured to keep the macronutrient ratios within target. The use of low- and noncaloric condiments (salt, pepper, spices, etc.) was encouraged to allow flavoring of meals but was not recorded due to the inability to track their minimal weight.

Snacks for between meals and before/during training sessions were collected each evening for intake on the following day. A further range of "free foods and drinks" (low energy fruits and vegetables, tea/coffee, water, and artificially sweetened beverages) was provided in the participants' living area, with a checklist noting some restrictions on portion sizes (LCHF diet), as well as the opportunity for each participant to report the day's intake at the next meal. Nutrition support during the twice weekly long training sessions and after key sessions was provided at the training site and recorded by the research team. $\mathrm{HCHO}$ and $\mathrm{PCHO}$ diets provided a targeted $\mathrm{CHO}$ intake of $\sim 60 \mathrm{~g} / \mathrm{hr}$ in the form of sports drinks, gels, and confectionery, while LCHF participants received an energy-matched equivalent in cheese or high-fat snack recipes, as well as noncaloric electrolyte supplements, to address the recommendations provided by the seminal book on this dietary philosophy (Volek \& Phinney, 2012). Posttraining recovery shakes provided $0.3 \mathrm{~g} / \mathrm{kg}$ highquality protein, and, in the case of the $\mathrm{HCHO}$ and $\mathrm{PCHO}$ diets, a $\mathrm{CHO}$ content of $1 \mathrm{~g} / \mathrm{kg}$.
Compliance with the dietary prescription and reporting requirements was checked daily. Completed weekly food records were analyzed during the following week to check that participants were meeting the goals of their prescribed diets.

\section{Analysis of Dietary Intake by Study Participants}

A computerized dietary analysis program (FoodWorks 8 Professional program; Xyris Software Australia Pty Ltd, Kenmore Hills, Australia) was used to analyze recipes, create meal plans, and estimate the actual energy, macronutrient, and micronutrient intake of each participant. Seven members of the research team trained in its use were responsible for all data entry and checking. Information on foods missing from the database was added according to a standardized protocol, with food companies being contacted to supply information that was not included on food labels. All intake was considered in the dietary analysis with the exception of noncaloric fluids, flavorings, and electrolyte supplements.

\section{Audit of Practical Issues}

A cost analysis was conducted for each diet, with prices for each food and recipe being calculated from published retail prices of an online supermarket purchasing service (Coles online; Coles Supermarkets Australia Pty Ltd, Melbourne, Australia) from February 9 to 19, 2016. Total costs for each participant were determined from actual consumption. Feedback from study participants and the dietary intervention team was recorded and used to discuss a range of issues such as ease of achieving special nutrition needs and food sustainability. 


\section{Statistical Analysis}

Statistical analyses were carried out with SPSS Statistics 22 (IBM, Armonk, NY) and Microsoft Excel 2016 (Microsoft, Redmond, WA). Gaussian distribution of energy, macronutrient and micronutrient intakes, and study costs was assessed with the ShapiroWilk goodness-of-fit test. Intake differences of the dietary interventions were analyzed with a one-way analysis of variance and Bonferroni post hoc testing when data were normally distributed. For data that were not normally distributed, the Kruskal-Wallis test was used. Results are shown as means $\pm S D$ s.

\section{Results}

Average daily energy, macronutrient, and micronutrient composition of the three diets (Table 4) shows that participants achieved the intended dietary manipulations, including the equivalent protein intake across all diets; similar average daily intake of $\mathrm{CHO}$ for $\mathrm{HCHO}$ and $\mathrm{PCHO}$, and marked differences in fat and $\mathrm{CHO}$ intake for LCHF when compared with PCHO and HCHO. Mean intakes of micronutrients exceeded the recommended dietary intakes from the Nutrient Reference Values for Australia and New Zealand (National Health and Medical Research Council, 2006). Micronutrient intakes and micronutrient density (per MJ energy) were similar in the $\mathrm{HCHO}$ and PCHO diets; however, values were consistently lower for the LCHF diet. The mean mass of food consumed per day (excluding sports drinks, coffee, tea, and low-energy beverages) was greater ( $p$ $<.001$ ) for HCHO and PCHO than LCHF.

The cost of the diets is summarized in Table 5. Differences between the three diets for average daily $(p=.072)$ or weekly $(p=.072)$ cost were not significant overall. However, when the cost of the gluten-free $\mathrm{HCHO}$ diet was removed from the analysis, the average weekly cost of the LCHF diet was greater than that of the HCHO $(p=.014)$. The total cost of these dietary interventions across the two camps was AU\$ 16,400.

\section{Discussion}

This paper demonstrates that: (a) rigorous implementation and monitoring of dietary interventions in a large-scale sports nutrition study require a high degree of resourcing and expertise; (b) in this specific study, the investigators were able to achieve a high degree of compliance to the three different dietary principles under investigation; and (c) the LCHF diet investigated in this study, representing an optimized interpretation of this philosophy, provided lower micronutrient density and less food volume/mass than diets based on higher $\mathrm{CHO}$ availability.

The complexity of undertaking dietary standardization and/or interventions in sports science research is often misunderstood and underestimated (Jeacocke \& Burke, 2010). This project involved considerable challenges, including three different dietary interventions over nearly 5 weeks (testing plus intervention periods), implementation and monitoring of up to 19 subjects simultaneously, provision of nutrition support at residential and several training locations, and integration of several nutritional characteristics within the macronutrient philosophies (e.g., energy availability targets, considerations around allergies/intolerances, food preferences). This was achieved via the creation of a dedicated research team, separate to the group involved in the laboratorybased investigations (Burke et al., 2017), comprised of chefs, sports dietitians, food service dietitians, and sports scientists with specific skills sets around menu planning, recipe development, food procurement and ordering, large quantity food preparation, food safety, and dietary analysis. Guidelines for strategic approaches to this work are summarized in Figure 1. The results of the final dietary analysis (Table 4) showed tight adherence to the planned interventions, with a small and matched loss of body fat $(\sim 1.4 \mathrm{~kg})$ across each group over 4 weeks (Burke et al., 2017) demonstrating that energy intakes achieved suitable energy availability. Obviously, the achievement of tight compliance with the implementation of extreme dietary changes, particularly in a large group of athletes, requires resources and expertise that may be beyond the capability of many research teams or sports settings. This should be taken into account prior to embarking on projects where the aim is to isolate the effect of dietary treatments. The authors have previously described other methods of achieving dietary standardization or the implementation of a dietary intervention, such as the provision of food to athletes to consume outside a supervised environment with checklists to monitor their adherence, or the use of dietary records to monitor compliance to self-selected diets following extensive education of the athlete (Jeacocke \& Burke, 2010). While the first of these methods can achieve apparently good compliance, it still involves considerable planning, expense, and manpower. In addition, menus may need to focus on foods that are preportioned or have minimal requirement for special storage and preparation needs. The second of the methods is less resource intensive and may have variable levels of compliance, depending on the complexity of the targeted diet and the motivation of participants. Hybrid protocols may also be used, such as having study participants choose their own food from a known and limited catering environment with the assistance of education resources. In any case, researchers should make careful decisions about the importance of the precision of dietary standardization or the achievement of a dietary intervention on the outcome variables of the study and allocate appropriate resources to achieve a suitable protocol.

Several other insights about the dietary interventions were gained. First, the study revealed some challenges and popular misconceptions about the LC HF diet. The principles of severe restriction of $\mathrm{CHO}(<\sim 50 \mathrm{~g} /$ day $)$ and moderate protein intake $(<\sim 2 \mathrm{~g} / \mathrm{kg} \mathrm{BM})$ to achieve chronic ketosis requires the elimination of many staple foods from the standard Western diet (e.g., most fruit, starchy vegetables and legumes, cereal products) and restrictions on the serving sizes of others. For example, there are portion limits on meats and cheeses within protein targets; carbohydrate targets restrict even high watercontent fruits (berries and tomatoes) to $100 \mathrm{~g} / \mathrm{day}$, with further limits on the intake of fat-rich fruits (avocadoes and olives) as well as the types and amounts of even high water-content vegetables that can be consumed within a 10- to $15-\mathrm{g} / \mathrm{day}$ CHO contribution (Volek \& Phinney, 2012). Serving sizes of nuts/seeds (limited to $60 \mathrm{~g} /$ day) and milk/yogurt need to be considered in the case of both macronutrients. Considerable skill was required to construct menus to meet the higher energy requirements of these athletes. To optimize micronutrient content of the LCHF menus, the use of whole foods was maximized and minimal amounts of processed foods were included, with occasional use of the desserts and treat foods (e.g., "fat bombs"), that are becoming more available commercially, featuring in "keto" recipe books or attracting large followings on social media around the LCHF diet. By contrast, the CHO-rich diets included compact and nutrient-poor convenience foods such as sports drinks, sports gels, and bars, as would typically be used by athletes.

Nevertheless, despite the best efforts to optimize the menu, the LCHF diet was associated with a lower food mass and a lower 
Table 4 Summary of Actual Daily Intake for Elite Race Walkers $(n=29)$ and Characteristics of Study Diets in Nutrition-Training Intervention (Burke et al., 2017) Involving HCHO, PCHO, and LCHF Approaches

\begin{tabular}{|c|c|c|c|c|c|}
\hline & \multirow[b]{2}{*}{ Goal intake } & \multirow[b]{2}{*}{ Units } & \multicolumn{3}{|c|}{ Mean daily intake } \\
\hline & & & НCHO & PCHO & LCHF \\
\hline \multirow[t]{2}{*}{ Energy } & & MJ & $14.73 \pm 1.66$ & $15.11 \pm 1.67$ & $14.54 \pm 2.38$ \\
\hline & & $\mathrm{MJ} / \mathrm{kg}$ & $0.23 \pm 0.01$ & $0.23 \pm 0.01$ & $0.22 \pm 0.03$ \\
\hline \multirow[t]{2}{*}{ Protein } & $\sim 2 \mathrm{~g} / \mathrm{kg}$ for all diets & $\mathrm{g}$ & $138 \pm 16$ & $148 \pm 19$ & $140 \pm 19$ \\
\hline & & $\mathrm{g} / \mathrm{kg}$ & $2.2 \pm 0.1$ & $2.2 \pm 0.1$ & $2.1 \pm 0.2$ \\
\hline \multirow[t]{2}{*}{ Carbohydrate } & 8-9 g/kg H/PCHO & $\mathrm{g} * * *, \mathfrak{f f \mathfrak { f }}$ & $549 \pm 64$ & $550 \pm 59$ & $33 \pm 7$ \\
\hline & $<0.5 \mathrm{~g} / \mathrm{kg} \mathrm{LCHF}$ & $\mathrm{g} / \mathrm{kg}^{* * *, \mathrm{ff}}$ & $8.6 \pm 0.4$ & $8.2 \pm 0.2$ & $0.5 \pm 0.1$ \\
\hline sugars & & $\mathrm{g} * * *, \mathfrak{f £ £}$ & $278 \pm 45$ & $288 \pm 34$ & $25 \pm 6$ \\
\hline starch & & $\mathrm{g} * * *, \mathfrak{f f \mathfrak { f }}$ & $274 \pm 33$ & $260 \pm 26$ & $8 \pm 1$ \\
\hline \multirow[t]{2}{*}{ Fat } & & $\mathrm{g}^{* * *, \mathfrak{E} \mathfrak{E}}$ & $77 \pm 9$ & $81 \pm 9$ & $304 \pm 51$ \\
\hline & & $\mathrm{g} / \mathrm{kg}^{*} * *, \mathfrak{x f f}$ & $1.2 \pm 0.06$ & $1.2 \pm 0.04$ & $4.6 \pm 0.5$ \\
\hline saturated & & $\mathrm{g} * * *, \mathfrak{f f \mathfrak { f }}$ & $29 \pm 2$ & $30 \pm 4$ & $145 \pm 25$ \\
\hline monounsaturated & & $\mathrm{g} * * *, \mathfrak{E}$ & $27 \pm 3$ & $31 \pm 3$ & $104 \pm 15$ \\
\hline polyunsaturated & & $\mathrm{g} * * *, \mathfrak{f} \mathfrak{f}$ & $12 \pm 1$ & $13 \pm 2$ & $28 \pm 5$ \\
\hline Cholesterol & & $\mathrm{mg} * * *, \mathfrak{E f f}$ & $331 \pm 42$ & $366 \pm 43$ & $931 \pm 167$ \\
\hline \multirow[t]{2}{*}{ Thiamin } & RDI: $1.2 \mathrm{mg} /$ day & $\mathrm{mg} * * *, \mathrm{fff}$ & $3.1 \pm 0.4$ & $3.3 \pm 0.4$ & $1.3 \pm 0.3$ \\
\hline & & $\mathrm{mg} / \mathrm{MJ} * * *, \mathfrak{f f f}$ & $0.21 \pm 0.01$ & $0.22 \pm 0.01$ & $0.09 \pm 0.01$ \\
\hline \multirow[t]{2}{*}{ Riboflavin } & RDI: $1.3 \mathrm{mg} / \mathrm{day}$ & $\mathrm{mg}^{*, \mathrm{f} £}$ & $3.4 \pm 0.6$ & $3.5 \pm 0.6$ & $2.7 \pm 0.4$ \\
\hline & & $\mathrm{mg} / \mathrm{MJ}$ & $0.23 \pm 0.02$ & $0.23 \pm 0.02$ & $0.19 \pm 0.05$ \\
\hline \multirow[t]{2}{*}{ Niacin equivalents } & RDI: 16 mg/day & $\mathrm{mg}^{\mathfrak{A f \mathfrak { E }}}$ & $57 \pm 6$ & $65 \pm 8$ & $50 \pm 7$ \\
\hline & & $\mathrm{mg} / \mathrm{MJ}^{* * *}, \# \# \#, \mathrm{fff}$ & $3.9 \pm 0.1$ & $4.3 \pm 0.1$ & $3.2 \pm 0.2$ \\
\hline \multirow[t]{2}{*}{ Vitamin $\mathrm{C}$} & RDI: 45 mg/day & $\mathrm{mg}^{*, \mathrm{fff}}$ & $251 \pm 61$ & $312 \pm 63$ & $183 \pm 38$ \\
\hline & & $\mathrm{mg} / \mathrm{MJ}^{*}, \mathrm{fff}$ & $17 \pm 5$ & $21 \pm 4$ & $13 \pm 1$ \\
\hline \multirow[t]{2}{*}{ Dietary folate equivalents } & RDI: $400 \mu \mathrm{g} /$ day & $\mu \mathrm{g}^{* * *, \mathrm{fff}}$ & $1,364 \pm 153$ & $1,448 \pm 175$ & $593 \pm 102$ \\
\hline & & $\mu \mathrm{g} / \mathrm{MJ} * * *$,f£f & $94 \pm 14$ & $96 \pm 3$ & $37 \pm 1$ \\
\hline \multirow[t]{2}{*}{ Retinol equivalents } & RDI: $900 \mu \mathrm{g} /$ day & $\mu \mathrm{g}^{* *, \mathrm{f£}}$ & $880 \pm 136$ & $967 \pm 143$ & $1,844 \pm 330$ \\
\hline & & $\mu \mathrm{g} / \mathrm{MJ} * * *, \mathfrak{f f f}$ & $60 \pm 8$ & $64 \pm 6$ & $127 \pm 5$ \\
\hline \multirow[t]{2}{*}{ Potassium } & AI: $3,800 \mathrm{mg} /$ day & $\mathrm{mg} * * *, \mathrm{Eff}$ & $5,358 \pm 767$ & $5,751 \pm 728$ & $3,572 \pm 630$ \\
\hline & & 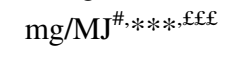 & $362 \pm 18$ & $380 \pm 16$ & $245 \pm 6$ \\
\hline \multirow[t]{2}{*}{ Magnesium } & RDI: 400 mg/day & $\mathrm{mg}$ & $586 \pm 74$ & $606 \pm 72$ & $544 \pm 95$ \\
\hline & & $\mathrm{mg} / \mathrm{MJ} * * *, \mathfrak{f \mathfrak { e }}$ & $40 \pm 1$ & $40 \pm 1$ & $37 \pm 1$ \\
\hline \multirow[t]{2}{*}{ Calcium } & RDI: $1,000 \mathrm{mg} /$ day & $\mathrm{mg}^{\mathfrak{f}}$ & $1,754 \pm 276$ & $1,776 \pm 330$ & $1,449 \pm 207$ \\
\hline & & $\mathrm{mg} / \mathrm{MJ} * * *, \mathfrak{e}$ & $119 \pm 9$ & $117 \pm 11$ & $100 \pm 8$ \\
\hline \multirow[t]{2}{*}{ Phosphorus } & RDI: $1,000 \mathrm{mg} /$ day & $\mathrm{mg}^{\mathfrak{E}}$ & $2,492 \pm 365$ & $2,651 \pm 354$ & $2,249 \pm 330$ \\
\hline & & $\mathrm{mg} / \mathrm{MJ} * * *, \mathrm{ff \mathfrak {f }}$ & $169 \pm 7$ & $175 \pm 6$ & $155 \pm 6$ \\
\hline \multirow[t]{2}{*}{ Iron } & RDI: $8 \mathrm{mg} /$ day & $\mathrm{mg} * * *, £ £ £$ & $17.7 \pm 2.0$ & $18.9 \pm 2.3$ & $13.4 \pm 2.6$ \\
\hline & & $\mathrm{mg} / \mathrm{MJ} * * *, \mathfrak{f \mathfrak { l }}$ & $1.2 \pm 0.0$ & $1.2 \pm 0.0$ & $0.9 \pm 0.1$ \\
\hline \multirow[t]{2}{*}{ Zinc } & RDI: 14 mg/day & $\mathrm{mg}$ & $17.3 \pm 2.2$ & $17.3 \pm 2.1$ & $15.8 \pm 2.6$ \\
\hline & & $\mathrm{mg} / \mathrm{MJ}^{\# \#, * * *, \mathfrak{f f} \mathfrak{f}}$ & $1.2 \pm 0.0$ & $1.1 \pm 0.0$ & $1.1 \pm 0.0$ \\
\hline
\end{tabular}

Note. Data are mean $\pm S D . \mathrm{CHO}=$ carbohydrate $\mathrm{HCHO}=$ high $\mathrm{CHO}$ availability $\mathrm{PCHO}=$ periodized $\mathrm{CHO}$ availability; $\mathrm{LCHF}=$ low $\mathrm{CHO}$ high fat $\mathrm{RDI}=$ recommended daily intake; $\mathrm{AI}=$ adequate intake (National Health and Medical Research Council, 2006).

${ }^{*} p<.05,{ }^{* *} p<.01, * * * p<.001$ differences between HCHO and LCHF. ${ }^{£} p<.05,{ }^{\mathrm{ff}} p<.01,{ }^{\mathrm{fff}} p<.001$ differences between PCHO and LCHF. ${ }^{\#} p<.05,{ }^{\# \#} p<.01$, $\ldots$ \#\# $p<.001$ differences between HCHO and PCHO.

intake and energy density of micronutrients than were the $\mathrm{HCHO}$ and PCHO diets. These findings are intuitive, given the extreme target (75-80\% of energy) from an energy-dense macronutrient and the need to eliminate or restrict many nutrient-dense or fortified foods from the eating plan. Nevertheless, the participants typically achieved micronutrient intakes that met recommended dietary intakes targets, although the lack of meal volume and loss of food variety was noted in their feedback. The mean potassium content of the LCHF diet was slightly less than the adequate intake (National Health and Medical Research Council, 2006), perhaps justifying the recommendations to consume electrolyte supplements while following this dietary philosophy (Volek \& Phinney, 2012). In the case of food allergies and intolerances, the LCHF was able to accommodate gluten-free needs more easily than the 
Table 5 Cost and Weight Comparison of HCHO, PCHO, and LCHF Diets for a 3-Week Diet Intervention

\begin{tabular}{lcccc}
\hline & HCHO & HCHO $^{2}$ & PCHO & LCHF \\
\hline Weekly cost per athlete (AU\$) & $175.10 \pm 32.33$ & $166.20^{* *} \pm 16.87$ & $192.79 \pm 22.63$ & $194.85 \pm 21.20$ \\
Daily cost per athlete (AU\$) & $25.02 \pm 4.62$ & $23.74 * * \pm 2.41$ & $27.54 \pm 3.23$ & $27.84 \pm 3.03$ \\
Average cost (AU\$)/MJ & $1.69 \pm 0.12$ & $1.65 \pm 0.04$ & $1.83 \pm 0.21$ & $1.90 \pm 0.30$ \\
Average daily weight (g) & $2,716 \pm 314$ & $2,645 \pm 233$ & $2,827 \pm 368$ & $1,549^{*} \pm 239$ \\
\hline
\end{tabular}

Note. Data are mean $\pm S D$. $\mathrm{CHO}=$ carbohydrate; $\mathrm{HCHO}=$ high $\mathrm{CHO}$ availability; $\mathrm{PCHO}=$ periodized $\mathrm{CHO}$ availability; $\mathrm{LCHF}=$ low $\mathrm{CHO}$ high fat; $\mathrm{HCHO}^{2}=$ removal of athlete requiring gluten-free diet from analysis.

*Difference between LCHF and all other diets $(p<.001)$. **Difference between LCHF and $\operatorname{HCHO}^{2}(p<.05)$.

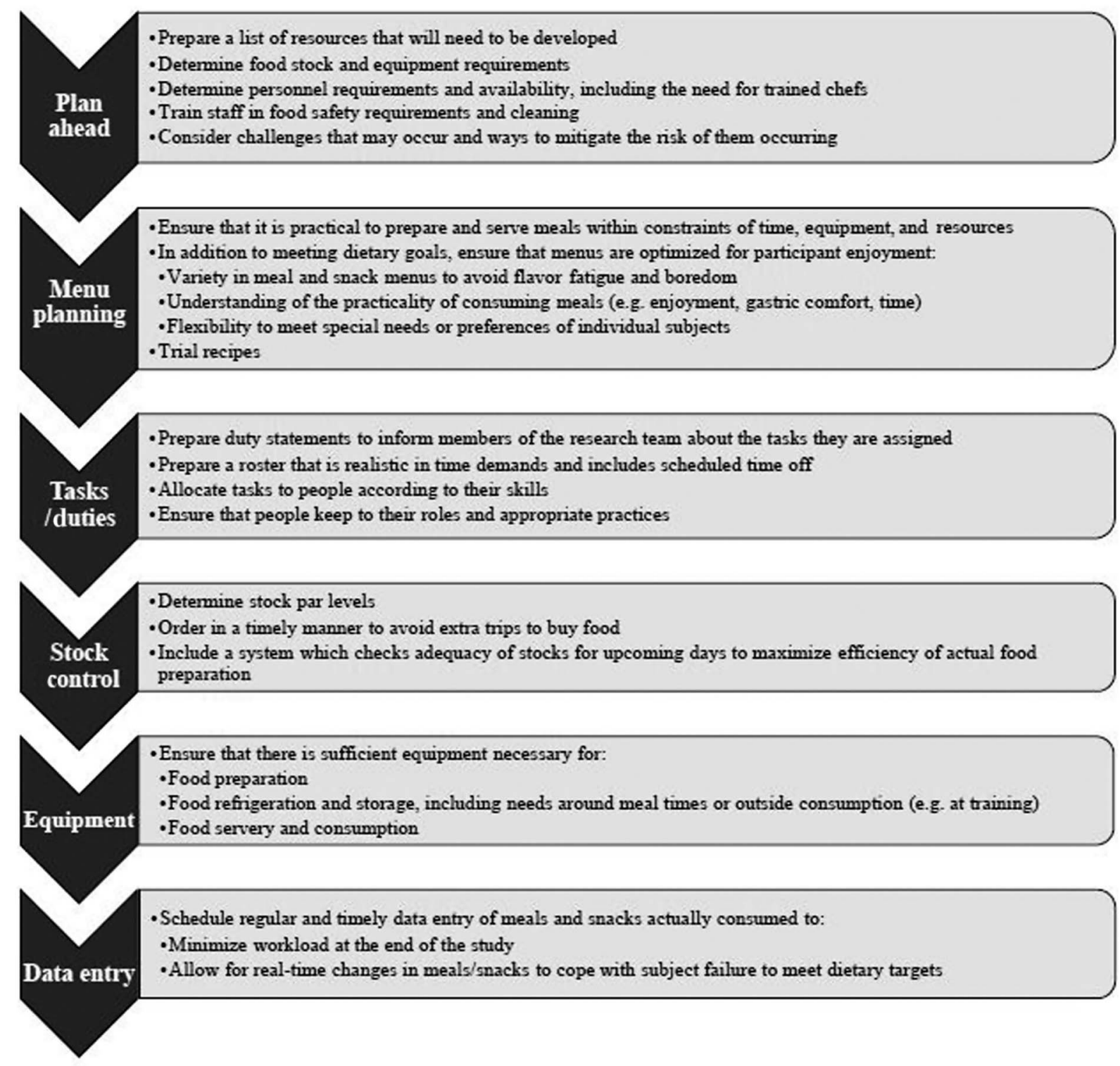

Figure 1 - Tips for successful implementation of a dietary intervention study.

PCHO and HCHO diets; however, nut or dairy allergies would create further challenges with food restrictions. These issues are of importance in critiquing the larger or long-term outcomes of dietary interventions under consideration, and potentially identifying other factors underpinning the results of lengthy studies. Although most dietary intervention studies typically report only the results of the energy and macronutrient intake of subjects, there may be some benefit in also considering the intake of key micronutrients, such as iron or calcium, which could lead to health issues if consumed at suboptimal levels for prolonged periods.

According to recent calculations by Lee et al. (2016), the fortnightly cost of a healthy diet basket for an Australian male is 
AU\$ $146.43 \pm 4.53$. The study diets were nearly twice as expensive due to their higher energy content, the use of specialized sports foods during training sessions, and the accommodation of special needs. When priced relative to energy content, the healthy basket was still lower, at AU\$ 0.11 per $100 \mathrm{~kJ}$ compared with AU\$ 0.17$\$ 0.19$ for the study diets. In the study diets, there was a trend to higher costs for the LCHF diet when compared with the HCHO. However, the cost of the $\mathrm{HCHO}$ diet was skewed by the need for one athlete to have gluten-free choices, and when adjusted for this, the LCHF diet was found to be more expensive than HCHO. A recent study on the affordability of a nutritionally balanced gluten-free diet in Australia found that it was considerably more expensive; for example, gluten-free flour, muesli, wraps, and bread may be $314-574 \%$ more expensive per $100 \mathrm{~g}$ than their regular counterpart (Lambert \& Ficken, 2015). The time taken to source appropriate foods and to obtain full nutrient composition information can add extra burden to a dietary study as well as to the daily commitments of a free-living athlete.

Food sustainability is a final factor to consider in dietary intervention/standardization studies and menu planning in general. This is particularly important in diets of restricted food variety or special needs, where it may be difficult to replace a key nutrient source. Issues of seasonality, source of supply, and shelf life of such foods may create some challenges, which may become more difficult with ongoing climate change (Melbourne Sustainable Society Institute, 2015). Indeed, this occurred in the January camp, when there was a reduction in the quality and availability of avocadoes (an LCHF staple) due to weather-related harvest delays and transportation issues (Webster, 2016). This increased food costs and the time spent sourcing product.

In summary, the current paper provides insight into the development of robust protocols for the implementation of dietary interventions in sports science research. The achievement of rigorous compliance to different dietary philosophies in intervention studies of this scale increases confidence in the detection and interpretation of study outcomes, leading to new sports nutrition knowledge as well as a greater understanding of the practical issues of achieving such diets in the real world.

\section{Acknowledgments}

J.G. Mirtschin and S.F. Forbes contributed equally to the work. The study concept was designed by L.M. Burke, and the diets were developed and implemented by L.M. Burke, J.G. Mirtschin, S.F. Forbes, L.E. Cato, I.A. Heikura, N. Strobel, and R. Hall. Data were collected and analyzed by J.G. Mirtschin, S.F. Forbes, L.E. Cato, and I.A. Heikura. Data interpretation and manuscript preparation were undertaken by L.M. Burke, J.G. Mirtschin, S.F. Forbes, and I.A. Heikura. All authors approved the final version of the paper. The authors thank the large Supernova team involved in the implementation of this study, and, particularly, the assistance of Emma Lindblom, Carolina Castellanos, Michelle Minehan, Julia Bone, Taryn Richardson, and Lynne Mercer for diet team activities and Melissa Holloway, Sarah Lau, and Larissa Maggs for cost analysis. Above all, the authors acknowledge the tremendous support and camaraderie of the athletes who consumed these diets to contribute to a greater understanding of optimal approaches to sports nutrition.

\section{References}

Bartlett, J.D., Hawley, J.A., \& Morton, J.P. (2015). Carbohydrate availability and exercise training adaptation: Too much of a good thing?
European Journal of Sport Science, 15, 3-12. PubMed ID: 24942068 doi:10.1080/17461391.2014.920926

Burke, L.M. (2015). Re-examining high-fat diets for sports performance: Did we call the 'nail in the Coffin' too soon? Sports Medicine, 45(Suppl. 1), S33-S49. doi:10.1007/s40279-015-0393-9

Burke, L.M., Kiens, B., \& Ivy, J.L. (2004). Carbohydrates and fat for training and recovery. Journal of Sports Sciences, 22(1), 15-30. doi:10.1080/0264041031000140527

Burke, L.M., Ross, M.L., Garvican-Lewis, L.A., Welvaert, M., Heikura, I.A., Forbes, S.F., . . Hawley, J.A. (2017). Low carbohydrate, high fat diet impairs exercise economy and negates the performance benefit from intensified training in elite race walkers. Journal of Physiology, 595, 2785-2807. PubMed ID: 28012184 doi:10.1113/JP273230

Coyle, E.F. (1991). Timing and method of increased carbohydrate intake to cope with heavy training, competition and recovery. Journal of Sports Sciences, 9, 29-52. doi:10.1080/02640419108729865

Jeacocke, N.A., \& Burke, L.M. (2010). Methods to standardize dietary intake before performance testing International Journal of Sport Nutrition and Exercise Metabolism, 20(2), 87-103.

Lambert, K., \& Ficken, C. (2015). Cost and affordability of a nutritionally balanced gluten-free diet: Is following a gluten-free diet affordable? Nutrition \& Dietetics, 73(1), 36-42. doi:10.1111/1747-0080.12171

Lee, A., Kane, S., Ramsey, R., Good, E., \& Dick, M. (2016). Testing the price and affordability of healthy and current (unhealthy) diets and the potential impacts of policy change in Australia. BMC Public Health, 16(1), 1-22.

Marquet, L.A., Brisswalter, J., Louis, J., Tiollier, E., Burke, L.M., Hawley, J.A., \& Hausswirth, C. (2016). Enhanced endurance performance by periodization of carbohydrate intake: "Sleep low" strategy. Medicine \& Science in Sports \& Exercise, 48, 663-672. PubMed ID: 26741119 doi:10.1249/MSS.0000000000000823

Melbourne Sustainable Society Institute. (2015). Appetite for change: Global warming impacts on food and farming regions in Australia. Melbourne, Australia: University of Melbourne. Retrieved from http://sustainable.unimelb.edu.au/sites/default/files/

MSSI_AppetiteForChange_Report_2015.pdf.

National Health and Medical Research Council, Australian Government Department of Health and Ageing, New Zealand Ministry of Health. (2006). Nutrient reference values for Australia and New Zealand. Canberra, Australia: National Health and Medical Research Council. Retrieved from https://www.nhmrc.gov.au/_files_nhmrc/file/ publications/17122_nhmrc_nrv_update-dietary_intakes.pdf

Papas, E., \& Papas, C. (2015). Make it merry: A healthy cookbook. Gold Coast, Australia: The Merrymaker Sisters.

Phinney, S.D., Bistrian, B.R., Evans, W.J., Gervino, E., \& Blackburn, G.L. (1983). The human metabolic response to chronic ketosis without caloric restriction: Preservation of submaximal exercise capacity with reduced carbohydrate oxidation. Metabolism, 32, 769-776. PubMed ID: 6865776 doi:10.1016/0026-0495(83)90106-3

Richoux, C. (2014). Bacon \& butter: The ultimate ketogenic diet cookbook. Berkley, CA: Callisto Media.

Thomas, D.T., Erdman, K.A., \& Burke, L.M. (2016). American College of Sports Medicine joint position statement. Nutrition and athletic performance. Medicine \& Science in Sports \& Exercise, 48, 543 568. PubMed ID: 26891166

Volek, J.S., \& Phinney, S.D. (2012). The art and science of low carbohydrate performance. Miami, FL: Beyond Obesity LLC.

Webster, L. (2016). Avocado prices hit record highs with increased demand and scarce supply. Retrieved from http://www.abc.net.au/ news/rural/2016-01-20/australian-avocado-prices-hit-record-highs/ 7099046 